\title{
Densidades e Manejo Químico da TiriRica na Produtividade de CANA-DE-AÇÚCAR ${ }^{1}$
}

\author{
Effects of Purple Nutsedge Plant Densities and Chemical Control on Sugarcane Yield
}

DURIGAN, J.C. ${ }^{2}$, TIMOSSI, P.C. ${ }^{3}$ e CORREIA, N.M. ${ }^{3}$

\begin{abstract}
RESUMO - Em dois experimentos instalados e conduzidos a campo, foram avaliados os efeitos de densidades da tiririca e do seu controle químico na produtividade da cana-deaçúcar (var. SP 86042). No primeiro, três densidades foram estudadas: baixa (58 a 246), média (318 a 773 ) e alta (675 a 1.198 manifestações epígeas $\mathrm{m}^{-2}$ ). As reduções na produção foram de 13,5, 29,3 e 45,2\% em relação à testemunha sem tiririca, respectivamente. No segundo experimento, foram testados os herbicidas sulfentrazone $\left(0,8 \mathrm{~kg} \mathrm{ha}^{-1}\right)$, imazapic $\left(0,105 \mathrm{~kg} \mathrm{ha}^{-1}\right)$ e flazasulfuron $\left(0,150 \mathrm{~kg} \mathrm{ha}^{-1}\right)$, em pré-emergência, além da mistura de trifloxysulfuron-sodium + ametryne e $\operatorname{Agral}^{\circledR}\left(1,5 \mathrm{~kg} \mathrm{ha}^{-1}+0,20 \%\right)$, halosulfuron + Aterbane ${ }^{\circledR}$ $\left(0,105 \mathrm{~kg} \mathrm{ha}^{-1}+0,25 \%\right)$ e flazasulfuron + Aterbane $^{\circledR}\left(0,150 \mathrm{~kg} \mathrm{ha}^{-1}+0,25 \%\right)$, em pós emergência. Nesta área, a variação de densidade foi de 66 a 154 plantas $\mathrm{m}^{-2}$. Aos 90 dias após o plantio (DAP), as porcentagens de controle foram de 79,$6 ; 70,6 ; 30,3 ; 84,8 ; 89,1$; e $61,1 \%$, respectivamente, para os herbicidas testados. A redução na produtividade foi de $16,4 \%$ entre as testemunhas infestada e capinada e de 11,9 e $6,0 \%$ onde se aplicou o flazasulfuron em pós e pré-emergência, respectivamente.
\end{abstract}

Palavras-chave: Cyperus rotundus, Saccharum ssp., herbicidas, seletividade.

ABSTRACT - The effects of purple nutsedge densities and chemical control on sugarcane (var. SP 86042) yield were evaluated. Three densities were studied: low (58 to 246), medium (318 to 773) and high (675 to 1198 shoots $\mathrm{m}^{-2}$ ). Yield reductions were 13.5; 29.3 and 45.2\% compared to the check, respectively. The importance of a good chemical control was evidenced in the second experiment with the herbicides sulfentrazone $\left(0.8 \mathrm{~kg} \mathrm{ha}^{-1}\right)$, imazapic $\left(0.105 \mathrm{~kg} \mathrm{ha}^{-1}\right)$ and flazasulfuron $(0.150 \mathrm{~kg} \mathrm{ha}$ ), at pre-emergence, and trifloxysulfuron-sodium + ametryne and surfactant (1.5 kg ha-1 $+0.25 \%)$, halosulfuron + surfactant (0.105 kg ha-1 $+0.20 \%)$ and flazasulfuron + surfactant $\left(0.150 \mathrm{~kg} \mathrm{ha} \mathrm{h}^{-1}+0.25 \%\right)$, at post-emergence. Density variation was from 66 to 154 shoots $m^{-2}$. At 90 days after planting (DAP), shoot control was 79.6; 70.6; 30.3; 84.8; 89.1 and $61.1 \%$, respectively, for the tested herbicides. Yield reduction of $16.4 \%$ was observed between the infested and weeded checks and of $11.9 \%$ and $6.0 \%$ in the plot with flazasulfuron applied at post and pre-emergence, respectively.

Key words: Cyperus rotundus, Saccharum ssp., herbicides, selectivity.

\section{INTRODUÇÃO}

Apesar de a cana-de-açúcar ser altamente eficiente na utilização dos recursos disponiveis para o seu crescimento, ela é muito afetada pela competição com as plantas daninhas, por apresentar, na maioria das situações, brotação e crescimento inicial lentos (Procópio et al., 2003).

A tiririca (Cyperus rotundus) é considerada a planta daninha mais disseminada e

Recebido para publicação em 17.3.2005 e na forma revisada em 5.9.2005.

Prof. Titular do Dep. de Fitossanidade da FCAV/UNESP, Via de acesso Prof. Paulo Donato Castellane, s/n., 14884-900 Jaboticabal-SP, <jcdurigan@fcav.unesp.br>; ${ }^{3}$ Eng-Agr., Doutorando em Produção Vegetal pela FCAV/UNESP, Jaboticabal-SP, <ptimossi2004@yahoo.com.br>. 
agressiva de todo o mundo, provocando reduções quantitativas e qualitativas na produção mundial das principais culturas (Cudney, 1997). Segundo Holm et al. (1977), a tiririca é a principal espécie daninha nos solos cultivados da região tropical. Nativa da Índia, infesta cerca de 52 importantes culturas em 92 países. Arévalo \& Bertoncini (1995) estimaram que metade dos solos agrícolas no Brasil está infestada com tiririca, independentemente de classes de solo, climas e culturas utilizadas.

Os tubérculos atuam como as principais unidades de dispersão, permanecendo dormentes no solo por longos períodos (Jakelaitis et al., 2003). Segundo Miles et al. (1996), a dormência dos tubérculos causa emergência irregular, e isso contribui para a persistência dessa planta daninha no solo. A taxa de produção de tubérculos, em boas condições edafoclimáticas, chega a ser de um a cada dois dias, e a densidade encontrada nos canaviais pode atingir 3.000 tubérculos $\mathrm{m}^{-2}$, com produção de até 2.000 manifestações epígeas $\mathrm{m}^{-2}$, as quais, após uma capina, crescem de um a três centímetros por dia (Lorenzi, 1983).

Quanto maior for a densidade da comunidade infestante, maior será a quantidade de indivíduos que disputam os mesmos recursos e, portanto, mais intensa será a interferência sofrida pela cultura (Pitelli, 1985). O limiar de dano econômico específico é a quantidade mínima de plantas de tiririca necessária para reduzir significativamente a produção de colmos e, conseqüentemente, de açúcar ou álcool, incrementar os custos de produção ou reduzir a qualidade do produto final. Apesar de vários trabalhos de pesquisa terem enfatizado os prejuízos ocasionados por altas densidades desta espécie daninha, ainda persistem dúvidas quanto aos seus efeitos deletérios à cana-de-açúcar, quando em baixas densidades.

Decorrente disso, dois experimentos foram conduzidos a campo com o objetivo de se conhecer o efeito de densidades crescentes de Cyperus rotundus e do seu manejo químico, em uma situação considerada de baixa densidade, sobre a produtividade da cana-deaçúcar.

Planta Daninha, Viçosa-MG, v. 23, n. 3, p. 463-469, 2005

\section{MATERIAL E MÉTODOS}

Foram instalados a campo, no ano agrícola de 2002-2003, dois experimentos na cultura da cana-de-açúcar var. SP 86042. Um dos experimentos foi instalado na Fazenda Boa Esperança, municipio de Taiúva-SP, onde três densidades, baixa (58 a 246), média (318 a 773) e alta (675 a 1.198 manifestações epígeas $\mathrm{m}^{-2}$ ), foram comparadas à testemunha sem tiririca. Foram obtidas as médias das densidades iniciais aos 30 dias após a emergência (DAE) da cana-soca (segundo corte) e, aos 125 DAE, as densidades máximas. As parcelas de cana - com cinco linhas espaçadas de 1,40 m e $10 \mathrm{~m}$ de comprimento cada - foram demarcadas em "manchas" com as diferentes densidades e repetidas por sete vezes. Para determinação da densidade de manifestações epígeas da parcela, foi lançado aleatoriamente, por dez vezes, quadro metálico, nas dimensões de $0,5 \times 0,5 \mathrm{~m}\left(0,25 \mathrm{~m}^{2}\right)$, totalizando $2,5 \mathrm{~m}^{2}$ de área amostrada. Foi avaliada a produtividade, em toneladas de colmos por hectare, colhendo-se as três linhas centrais com $9 \mathrm{~m}$ de comprimento, após desprezar-se 0,5 m de cada extremidade. O delineamento experimental foi o inteiramente casualizado, com quatro tratamentos e sete repetições.

No segundo experimento, instalado na Fazenda Bela Vista, município de Monte Alto-SP, foram utilizados os herbicidas sulfentrazone $\left(0,8 \mathrm{~kg} \mathrm{ha}^{-1}\right)$, imazapic $\left(0,105 \mathrm{~kg} \mathrm{ha}^{-1}\right)$ e flazasulfuron $\left(0,150 \mathrm{~kg} \mathrm{ha}^{-1}\right)$, em pré-emergência, além da mistura pronta de trifloxysulfuron-sodium + ametryne e $\mathrm{Agral}^{\circledR}$ $\left(1,5 \mathrm{~kg} \mathrm{ha}^{-1}+0,20 \%\right)$, halosulfuron + Aterbane $^{\circledR}$ $\left(0,105 \mathrm{~kg} \mathrm{ha}^{-1}+0,25 \%\right)$ e flazasulfuron + Aterbane $^{\circledR}\left(0,150 \mathrm{~kg} \mathrm{ha}^{-1}+0,25 \%\right)$, em pósemergência. Nessa área de cana-planta, a variação de densidade foi de 66 manifestações epígeas $\mathrm{m}^{-2}$, no plantio, até 154, após 125 dias. A aplicação, em pré-emergência, foi realizada no dia do plantio e, em pós-emergência, aos 30 dias após o plantio (DAP), quando as plantas de tiririca mediam $0,15 \mathrm{~m}$ de altura e possuíam 4 a 5 folhas desenvolvidas. Para as duas épocas de aplicação, utilizou-se um pulverizador pressurizado com $\mathrm{CO}_{2}$, a pressão constante de 2, $1 \mathrm{kgf} \mathrm{cm}^{-2}$, acoplado a uma barra contendo seis bicos com pontas de jato plano DG 11002 espaçados de 0,5 m, com consumo de calda equivalente a $200 \mathrm{~L} \mathrm{ha}^{-1}$. 
Foram feitas avaliações de densidade da tiririca aos $31,65,90$ e 125 dias após a aplicação (DAA) em pré-emergência e aos 35, 60 e 95 dias da aplicação realizada em pós-emergência. Amostrou-se $0,5 \mathrm{~m}^{2}$ por parcela com auxílio de quadro metálico, nas dimensões de 0,5 x 0,5 m, lançado duas vezes na área. Nessas respectivas épocas também foram atribuidas notas, visualmente, para os sintomas de intoxicação nas plantas de cana, com base na escala de notas do EWRC (1964).

O número de colmos em $8 \mathrm{~m}$, de uma das linhas da área útil, foi avaliado aos 65 DAA, em pós-emergência. A altura, até a última lígula visível, de dez plantas em linha, foi medida aos 65 e 125 DAP. Nessa segunda época também se procedeu à avaliação de tubérculos brotados, dormentes e inviáveis, segundo metodologia proposta por Delouche et al. (1962), retirando-se 50 tubérculos do total de quatro amostras $(0,30 \times 0,30 \times 0,20 \mathrm{~m})$ realizadas $\mathrm{em}$ cada parcela. A produtividade de colmos, em $\mathrm{t} \mathrm{ha} \mathrm{h}^{-1}$, foi avaliada na colheita. O delineamento experimental foi o de blocos casualizados, com sete tratamentos e quatro repetições. As parcelas constaram de quatro linhas de plantio da cultura da cana-de-açúcar, espaçadas de $1,4 \mathrm{~m}$, com 10 metros de comprimento, totalizando $56 \mathrm{~m}^{2}$.

Para detecção de diferenças significativas entre os tratamentos, foi feita a análise de variância, pelo teste $\mathrm{F}$. Na comparação de médias foi utilizado o teste de Tukey a 5\% de probabilidade. Aplicou-se também a análise de regressão para determinação do efeito das densidades de tiririca na produtividade da cana-de-açúcar.

\section{RESULTADOS E DISCUSSÃO}

A produtividade de colmos de cana-deaçúcar, em t ha-1, em três densidades de tiririca, é apresentada na Tabela 1. Houve redução dessa prodituvidade com o aumento das densidades da planta daninha. Na densidade considerada baixa a redução foi de 13,5\%; na intermediária, de 29,3\%; e na alta, de $45,2 \%$.

O número de manifestações epígeas é uma característica estreitamente relacionada com a produção de rizomas e tubérculos (Willians, 1978) e, conseqüentemente, com as habilidades alelopáticas e competitivas da planta (Durigan, 1991). Proporcionalmente, foi maior a redução da produção em baixa densidade, mostrando que a importância do indivíduo como elemento competitivo fica diminuída nas mais altas (Blanco, 1972). No entanto, é possivel visualizar que o potencial de redução na produção manter-se-ia para outros incrementos na densidade. A análise de regressão linear (para as infestações inicial e final) ratifica essa assertiva, evidenciando correlação negativa e significativa $(r=-0,97$ e $r=-0,99)$ entre essas características (Figura 1).

No segundo experimento também se constatou incremento no número de manifestações epígeas no início do ciclo da cana-planta, conforme mostram as avaliações feitas desde zero até 125 DAP (Tabela 2). Apesar de inicialmente baixa (66 $\mathrm{m}^{-2}$ na primeira avaliação), houve rápido incremento $\left(211 \mathrm{~m}^{-2}\right)$, em face da grande capacidade de reprodução vegetativa da planta daninha, nos primeiros 90 dias. Posteriormente, houve estabilização no número de manifestações epígeas (154 plantas $\mathrm{m}^{-2}$ ), em razão do forte sombreamento imposto pelas plantas de cana, aos 125 DAP. Na verdade, a densidade inicial, considerada baixa, aumentou, e um maior número de plantas permaneceu junto com a cultura durante o restante do seu ciclo.

Tabela 1 - Efeito de densidades de tiririca (Cyperus rotundus) na produtividade da cana-de-açúcar (var. SP 86042). Taiúva-SP, 2002

\begin{tabular}{|c|c|c|c|}
\hline \multicolumn{2}{|c|}{$\begin{array}{c}\text { Densidades } \\
\text { (manifestações epígeas } \mathrm{m}^{-2} \text { ) }\end{array}$} & \multirow{2}{*}{$\begin{array}{c}\text { Colmos } \\
\left(\mathrm{t} \mathrm{ha}^{-1}\right)\end{array}$} & \multirow{2}{*}{$\% \mathrm{RRT}$} \\
\cline { 1 - 2 } Inicial (I) & Final (F) & & \\
\hline 0 & 0 (Test.) ${ }^{*}$ & $136,0 \mathrm{a}^{1}$ & - \\
\hline 58 & 246 (baixa) & $117,7 \mathrm{~b}$ & 13,5 \\
\hline 318 & 773 (média) & $96,1 \mathrm{c}$ & 29,3 \\
\hline 675 & 1.198 (alta) & $74,6 \mathrm{~d}$ & 45,2 \\
\hline $\mathrm{F}$ & & $39,56^{* *}$ & \\
\hline CV(\%) & & 10,5 & \\
\hline Dms a 5\% & & 16,5 & \\
\hline
\end{tabular}

1/ Médias seguidas da mesma letra, numa mesma coluna, não diferem entre si pelo teste de Tukey $(\mathrm{P}>0,05)$; * Médias de sete repetições; I avaliação inicial (30 DAE - cana-soca); F - avaliação final (125 DAE - cana-soca); DAE - dias após emergência; RRT - redução em relação à testemunha sem tiririca. 

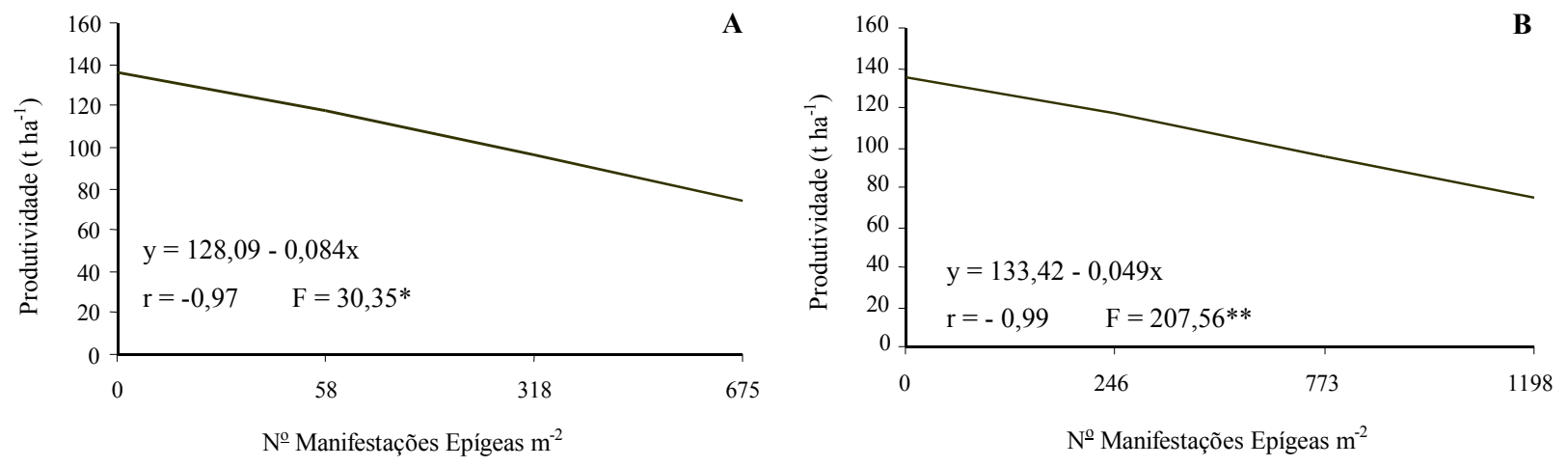

Figura 1 - Efeito de densidades, inicial (A) e final (B), de tiririca (Cyperus rotundus) na produtividade da cana-de-açúcar (var. SP 86042). Taiúva-SP, 2002.

Tabela 2 - Números de manifestações epígeas de tiririca por $\mathrm{m}^{2}$ e porcentagens de controle químico em diferentes períodos do início do ciclo da cana-planta (var. SP 86042). Monte Alto-SP, 2002

\begin{tabular}{|c|c|c|c|c|c|c|}
\hline \multirow{2}{*}{$\begin{array}{l}\text { Herbicida e dose } \\
\qquad\left(\mathrm{kg} \mathrm{ha}^{-1}\right)\end{array}$} & \multirow{2}{*}{$\begin{array}{l}\text { Época de } \\
\text { aplicação }\end{array}$} & \multicolumn{5}{|c|}{ Número de manifestações epígeas $\mathrm{m}^{-2} \mathrm{e}(\%$ controle $)$} \\
\hline & & & $31 \mathrm{DAP}$ & 65 DAP & 90 DAP & 125 DAP \\
\hline Sulfentrazone $(0,8)$ & pré & & $3(96,9)$ & $12(93,5) \mathrm{c}^{1 / /}$ & $43(79,6) \mathrm{cd}$ & $61(60,4) b$ \\
\hline Imazapic $(0,105)$ & pré & & $8(91,7)$ & $18(90,3) b c$ & $62(70,6) \mathrm{cd}$ & $58(62,3) \mathrm{b}$ \\
\hline Flazasulfuron $(0,150)$ & pré & & $28(71,1)$ & $74(60,0) b$ & $147(30,3) b$ & $125(18,8) \mathrm{a}$ \\
\hline & & & & 35 DAA & 60 DAA & 95 DAA \\
\hline Triflox.-sodium+ ametryne e Agral $(1,5+0,20 \%)$ & pós & & & $21(88,6) b c$ & $32(84,8) \mathrm{cd}$ & $54(64,9) b$ \\
\hline Halosulfuron + Aterbane $(0,105+0,25 \%)$ & pós & & & $18(90,3) b c$ & $23(89,1) \mathrm{d}$ & $48(68,8) \mathrm{b}$ \\
\hline Flazasulfuron + Aterbane $(0,15+0,25 \%)$ & pós & & & $42(77,2) \mathrm{bc}$ & $82(61,1) \mathrm{c}$ & $81(47,4) b$ \\
\hline & & 0 DAP & 31 DAP & 65 DAP & 90 DAP & $125 \mathrm{DAP}$ \\
\hline Testemunha infestada & & 66 & 97 & $185(0,0) \mathrm{a}$ & $211(0,0) \mathrm{a}$ & $154(0,0) \mathrm{a}$ \\
\hline $\mathrm{F}$ & & & & $22,15^{* *}$ & $32,11 * *$ & $22,21 * *$ \\
\hline $\mathrm{CV}(\%)$ & & & & 51,8 & 28,5 & 20,9 \\
\hline dms a $5 \%$ & & & & 61,9 & 57,0 & 40,5 \\
\hline
\end{tabular}

1/ Médias seguidas da mesma letra, numa mesma coluna, não diferem entre si pelo teste de Tukey (P> 0,05); plantio: 15.2.2002; aplicação (pré): 15.2.2002; aplicação (pós): 17.3.2002; DAP = dias após plantio.

No auge da produção de novas partes aéreas (90 DAP), refletindo o intenso metabolismo das plantas de tiririca, foram constatados bons resultados de controle para os herbicidas aplicados em pós-emergência, com 84,8 e $89,1 \%$, respectivamente para a mistura pronta de trifloxysulfuron-sodium + ametryne e halosulfuron (Tabela 2). No caso dos herbicidas aplicados em pré-emergência, os percentuais de controle foram de 79,6 e 70,6\%, para sulfentrazone e imazapic, respectivamente. $\mathrm{O}$ flazasulfuron, em ambos os tipos de aplicação, não proporcionou resultados promissores nessa época. Durigan et al. (2004) obtiveram porcentagem de controle superior a $80 \%$ para a tiririca, avaliada aos 90 DAA, com os herbicidas sulfentrazone e imazapic.

Planta Daninha, Viçosa-MG, v. 23, n. 3, p. 463-469, 2005
Todos os herbicidas foram seletivos às plantas de cana-de-açúcar (Tabela 3). O imazapic, em pré-emergência, e o flazasulfuron, em pós, foram os que mantiveram sintomas de intoxicação mais duradouros, apresentando clorose generalizada das folhas e retardo inicial do desenvolvimento, além da redução no número de plantas ocasionada pelo primeiro (Tabela 4), até 65 DAA. As alturas das plantas também não tiveram modificações significativas em relação à testemunha capinada. Durigan et al. (2004) observaram os mesmos sintomas de intoxicação de plantas de cana-de-açúcar var. RB 806043 para o herbicida imazapic. Azânia et al. (2001) verificaram que os sintomas de intoxicação de plantas provocados pelo imazapic são leves, sendo imperceptiveis a 
partir dos 100 DAA, além de não interferirem na produtividade da cultura da cana-de-açúcar. Furuhashi et al. (2000) não constataram diferenças estatísticas para a altura de plantas de cana-de-açúcar das variedades SP 791011 e RB 855536, apresentando sintomas leves de intoxicação, quando adicionados diferentes surfatantes à calda com flazasulfuron.

A redução na produção foi de $16,4 \%$ entre as testemunhas infestada e capinada, o que comprova a ação prejudicial dessa planta daninha mesmo em densidades consideradas baixas. Em face dos menores resultados de controle, houve redução de 11,9 e $6,0 \%$ na produtividade onde se aplicou o flazasulfuron, em pós e pré-emergência, respectivamente.

Ainda neste experimento, foram avaliados os percentuais de tubérculos brotados, dormentes e inviáveis, aos 125 DAP (Tabela 5). Efetivamente, consegue-se redução significativa na infestação desta planta daninha, de um ano para o outro, se houver efetiva ação do herbicida na supressão da sua capacidade reprodutiva, complementada pelo sombreamento eficaz e precoce das plantas de canade-açúcar.

A capacidade de inviabilização de tubérculos apresentada pelos herbicidas sulfentrazone $(78 \%)$, trifloxysulfuron-sodium + ametryne (70\%), imazapic (64\%) e halosulfuron $(50 \%)$ os credencia para a recomendação em aplicações isoladas ou de manejo integrado desta planta daninha. Durigan et al. (2004), quando integraram o uso de herbicidas à palha residual da cana, para o controle de tiririca, constataram que a mistura pronta

Tabela 3 - Notas atribuídas visualmente para os sintomas de intoxicação nas plantas de cana-de-açúcar (var. SP 86042) após a aplicação dos herbicidas, em pré e pós-emergência. Monte Alto-SP, 2002

\begin{tabular}{|c|c|c|c|c|c|}
\hline \multirow{2}{*}{$\begin{array}{l}\text { Herbicida e dose } \\
\qquad\left(\mathrm{kg} \mathrm{ha}^{-1}\right)\end{array}$} & \multirow{2}{*}{$\begin{array}{l}\text { Época de } \\
\text { aplicação }\end{array}$} & \multicolumn{4}{|c|}{ Notas de fitotoxicidade $*$} \\
\hline & & $31 \mathrm{DAA}$ & $65 \mathrm{DAA}$ & $90 \mathrm{DAA}$ & $125 \mathrm{DAA}$ \\
\hline Sulfentrazone $(0,8)$ & pré & 1,0 & 1,0 & 1,0 & 1,0 \\
\hline Imazapic $(0,105)$ & pré & 3,5 & 5,0 & 2,8 & 2,0 \\
\hline Flazasulfuron $(0,150)$ & pré & 1,0 & 1,7 & 1,5 & 1,0 \\
\hline testemunha capinada & - & 1,0 & 1,0 & 1,0 & 1,0 \\
\hline & & $35 \mathrm{DAA}$ & $60 \mathrm{DAA}$ & 95 DAA & - \\
\hline Triflox. sodium+ ametryne e Agral $(1,5+0,20 \%)$ & pós & 2,5 & 3,0 & 1,0 & - \\
\hline Halosulfuron + Aterbane $(0,105+0,25 \%)$ & pós & 2,0 & 3,0 & 1,0 & - \\
\hline Flazasulfuron + Aterbane $(0,15+0,25 \%)$ & pós & 5,5 & 5,0 & 3,0 & - \\
\hline
\end{tabular}

Plantio: 15.2.2002; aplicação (pré): 15.2.2002; aplicação (pós): 17.3.2002; DAA = dias após aplicação; * Escala EWRC (1964).

Tabela 4 - Número, altura e produção de colmos da cana-de-açúcar (var. SP 86042), submetida à aplicação de herbicidas, em pré e pós-emergência, para o controle da tiririca. Monte Alto-SP, 2002

\begin{tabular}{|c|c|c|c|c|c|c|}
\hline \multirow{2}{*}{$\begin{array}{l}\text { Herbicida e dose } \\
\quad\left(\mathrm{kg} \mathrm{ha}^{-1}\right)\end{array}$} & \multirow{2}{*}{$\begin{array}{l}\text { Época de } \\
\text { aplicação }\end{array}$} & \multirow{2}{*}{$\begin{array}{c}\text { № plantas } / 8 \mathrm{~m} \\
65 \mathrm{DAA}\end{array}$} & \multicolumn{2}{|c|}{ Altura plantas $(\mathrm{cm})$} & \multirow{2}{*}{$\begin{array}{c}\text { Produção de } \\
\text { colmos }\left(\mathrm{t} \mathrm{ha}^{-1}\right)\end{array}$} & \multirow{2}{*}{$\%$ RRT } \\
\hline & & & $65 \mathrm{DAP}$ & 125 DAP & & \\
\hline Sulfentrazone $(0,8)$ & pré & $120 \mathrm{a}^{1 /}$ & 61,0 & $240,2 \mathrm{ab}$ & $142 \mathrm{a}$ & 0,0 \\
\hline Imazapic $(0,105)$ & pré & $102 \mathrm{~b}$ & 58,0 & $236,8 \mathrm{ab}$ & $138 \mathrm{a}$ & 0,0 \\
\hline Flazasulfuron $(0,150)$ & pré & $118 \mathrm{ab}$ & 59,5 & $234,3 \mathrm{ab}$ & $126 \mathrm{abc}$ & 6,0 \\
\hline Trif--sodium+ ametryne e Agral $(1,5+0,20 \%)$ & pós & $118 \mathrm{ab}$ & 60,3 & $240,0 \mathrm{ab}$ & $136 \mathrm{a}$ & 0,0 \\
\hline Halosulfuron + Aterbane $(0,105+0,25 \%)$ & pós & $117 \mathrm{ab}$ & 61,8 & $246,3 \mathrm{a}$ & $132 \mathrm{ab}$ & 1,5 \\
\hline Flazasulfuron + Aterbane $(0,150+0,25 \%)$ & pós & $106 \mathrm{ab}$ & 52,1 & $235,4 \mathrm{ab}$ & $118 \mathrm{bc}$ & 11,9 \\
\hline Testemunha infestada & - & $102 \mathrm{~b}$ & 55,0 & $225,7 \mathrm{~b}$ & $112 \mathrm{c}$ & 16,4 \\
\hline Testemunha capinada & - & $113 \mathrm{ab}$ & 59,9 & $239,2 \mathrm{ab}$ & $134 \mathrm{ab}$ & - \\
\hline$F$ & & $4,34 * *$ & $0,96^{\text {ns }}$ & $2,77 *$ & $8,99 * *$ & \\
\hline $\mathrm{CV}(\%)$ & & 6,5 & 14,3 & 3,1 & 5,3 & \\
\hline dms a $5 \%$ & & 17,2 & 19,4 & 17,4 & 16,4 & \\
\hline
\end{tabular}

${ }^{1 /}$ Médias seguidas da mesma letra, na coluna, não diferem entre si pelo teste de Tukey $(\mathrm{P}>0,05)$; DAP $=$ dias após plantio; DAA $=$ dias após aplicação; RRT = redução em relação à testemunha capinada. 
Tabela 5 - Percentuais de tubérculos brotados, dormentes e inviáveis, aos 125 dias após o plantio (DAP) da cana-de-açúcar (var. SP 86042), submetida à aplicação de herbicidas, em pré e pós-emergência, para o controle da tiririca. Monte Alto-SP, 2002

\begin{tabular}{|c|c|c|c|c|}
\hline \multirow{2}{*}{$\begin{array}{l}\text { Herbicidas e Doses } \\
\qquad\left(\mathrm{kg} \mathrm{ha}^{-1}\right)\end{array}$} & \multirow{2}{*}{ Aplicação } & \multicolumn{3}{|c|}{$\%$ tubérculos ${ }^{2 /}$} \\
\hline & & Brotados & Dormentes & Inviáveis \\
\hline Sulfentrazone $(0,8)$ & pré & $12 \mathrm{c}^{\underline{1} /}$ & $10 \mathrm{ab}$ & $78 \mathrm{a}$ \\
\hline Imazapic $(0,105)$ & pré & $26 \mathrm{c}$ & $10 \mathrm{ab}$ & $64 \mathrm{abc}$ \\
\hline Flazasulfuron $(0,150)$ & pré & $50 \mathrm{~b}$ & $9 \mathrm{~b}$ & $41 \mathrm{~cd}$ \\
\hline Trifl.-sodium+ametry. e Agral $(1,5+0,20 \%)$ & pós & $21 \mathrm{c}$ & $13 \mathrm{ab}$ & $70 \mathrm{ab}$ \\
\hline Halosulfuron + Aterbane $(0,105+0,25 \%)$ & pós & $31 \mathrm{bc}$ & $19 \mathrm{a}$ & $50 \mathrm{bcd}$ \\
\hline Flazasulfuron + Aterbane $(0,150+0,25 \%)$ & pós & $53 \mathrm{~b}$ & $11 \mathrm{ab}$ & $36 \mathrm{~d}$ \\
\hline Testemunha infestada & - & $78 \mathrm{a}$ & $15 \mathrm{ab}$ & $7 \mathrm{e}$ \\
\hline $\begin{array}{l}\mathrm{F} \\
\ldots \ldots\end{array}$ & & $25,28 * *$ & $3,33^{*}$ & $20,61 * *$ \\
\hline $\mathrm{CV}(\%)$ & & 25,8 & 32,1 & 21,4 \\
\hline dms a $5 \%$ & & 22,2 & 9,5 & 24,6 \\
\hline
\end{tabular}

${ }^{1 /}$ Médias seguidas da mesma letra, numa mesma coluna, não diferem entre si pelo teste de Tukey (P> 0,05); ${ }^{2 / 50}$ tubérculos de quatro amostras $(0,30 \times 0,30 \times 0,20 \mathrm{~m})$, uma em cada parcela.

trifloxysulfuron-sodium + ametryne foi a única que apresentou capacidade de inviabilização de tubérculos semelhante à do sulfentrazone, quando na ausência de palha residual da cana-de-açúcar. Segundo Schumm et al. (2002), o trifloxysulfuron-sodium + ametryne pode ser boa alternativa para reduzir o número de tubérculos de tiririca, quando usado em anos consecutivos em área infestada.

Com base nos resultados obtidos, pôde-se concluir que a tiririca reduziu a produção da variedade SP 86042 mesmo nas densidades consideradas baixas. Os herbicidas trifloxysulfuron-sodium + ametryne, sulfentrazone, imazapic e halosulfuron constituiram-se em boas opções para o manejo da tiririca, em virtude da seletividade para cana-de-açúcar e atuação eficaz na supressão da parte subterrânea dessa planta daninha.

\section{LITERATURA CITADA}

ARÉVALO, R. A.; BERTONCINI, E. I. Efeito e manejo de Cyperus rotundus (tiririca) na agricultura brasileira. In: CONGRESSO BRASILEIRO DA CIÊNCIA DAS PLANTAS DANINHAS, 20., 1995, Florianópolis. Palestra... Florianópolis: Sociedade Brasileira da Ciência das Plantas Daninhas, 1995. p. 45-66.

AZÂNIA, C. A. M.; CASAGRANDE, A. A.; ROLIM, J. C. Seletividade de imazapic às soqueiras de cana-de-açúcar (Saccharum spp.). Planta Daninha, v. 19, n. 3, p. 345$350,2001$.

Planta Daninha, Viçosa-MG, v. 23, n. 3, p. 463-469, 2005
BLANCO, H. G. A importância dos estudos ecológicos nos programas de controle das plantas daninhas. O Biológico, v. 38 , n. 6 , p. 343-350, 1972.

CUDNEY, D. Nutsedge: history, economy, importance and distribution. In: NUTSEDGE Management Workshop. Riverside: University of California, 1997. Disponível em: $<$ http://www.cnas.ucr.edu/ bps/hnutsedge.htm>. Acesso em: 15 abr. 2005.

DELOUCHE, J. C. et al. The tetrazolium test for seed viability. Miss. Agric. For. Exp. St. Tech. Bull., v. 5, p. 1-63, 1962.

DURIGAN, J. C. Manejo da tiririca (Cyperus rotundus L.) antes e durante a implantação da cultura da cana-deaçúcar (Saccharum spp.). 1991. 336 f. Tese (LivreDocência) - Universidade Estadual Paulista, Jaboticabal, 1991.

DURIGAN, J. C.; TIMOSSI, P. C.; LEITE, G. J. Controle químico da tiririca (Cyperus rotundus), com e sem cobertura do solo pela palha de cana-de-açúcar. Planta Daninha, v. 22 , n. 1, p. 127-135, 2004.

EUROPEAN WEED RESEARCH COUNCIL - EWRC. Report of the $3^{\text {rd }}$ and $4^{\text {th }}$ meetings of EWRC - Comittee of Methods in Weed Research. Weed Res., v. 4, n. 1, p. 88, 1964.

FURUHASHI, S. et al. Efeito fitotóxico de flazasulfuron em três cultivares de cana-de-açúcar (Saccharum spp.). In: CONGRESSO BRASILEIRO DA CIÊNCIA DAS PLANTAS DANINHAS, 22., 2000, Foz do Iguaçu. Resumos... Foz do Iguaçu: Sociedade Brasileira da Ciência das Plantas Daninhas, 2000. p. 314.

HOLM, L. G. et al. The world's worst weeds: distribution and biology. Honolulu: University Press of Hawaii, 1977. $609 \mathrm{p}$. 
JAKELAITIS, A. et al. Efeitos de sistemas de manejo sobre a população de tiririca. Planta Daninha, v. 21, n. 1, p. 89-95, 2003.

LORENZI, H. J. Plantas daninhas e seu controle na cultura da cana-de-açúcar. In: REUNIÃO TÉCNICA

AGRONÔMICA - pragas da cultura da cana-de-açúcar, 1983, Piracicaba. Anais... Piracicaba: 1983. p. 59-73.

MILES, J. E.; NISHIMOTO, R. K.; KAWABATA, O.

Diurnally alternating temperatures stimulates sprouting of purple nutsedge (Cyperus rotundus) tubers. Weed Sci., v. 44, p. 122-125, 1996.

PITELLI, R. A. Interferência de plantas daninhas em culturas agrícolas. Inf. Agropec., v. 11, n. 129, p. 16-27, 1985.
PROCÓPIO, S. O. et al. Manejo de plantas daninhas na cultura da cana-de-açúcar. Viçosa-MG: Universidade Federal de Viçosa, 2003. 150 p.

SCHUMM, K. C.; BOSQUE, J. J.; SOARES, J. E. Controle de tiririca em cana-de-açúcar com trifloxysulfuron sodium + ametrina, através de aplicação programada de vários anos. In: CONGRESSO BRASILEIRO DA CIÊNCIA DAS PLANTAS DANINHAS, 23., 2002, Gramado. Resumos... Gramado: Sociedade Brasileira da Ciência das Plantas Daninhas, 2002. p. 504.

WILLIAMS, R. D. Photoperiod effects on the reproductive biology of purple nutsedge (Cyperus rotundus L.). Weed Sci., v. 26, n. 6, p. 539-542, 1978. 